
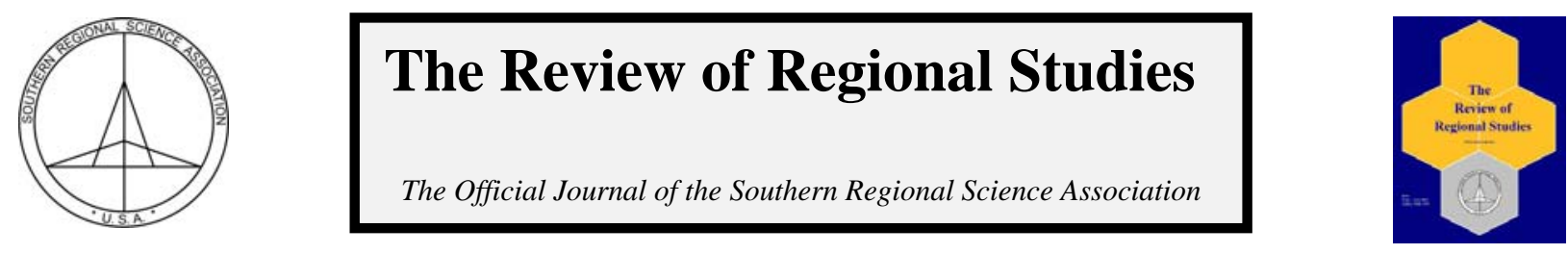

\title{
Determinants of Innovative Versus Non-Innovative Entrepreneurs in Three Southern States
}

\author{
Roberto Gallardo and Roseanne Scammahorn
}

Southern Rural Development Center, Mississippi State University USA

\begin{abstract}
Entrepreneurship is becoming an important economic development strategy for communities across the nation. This research distinguishes between innovative and non-innovative entrepreneurs as well as "traditional" entrepreneurs - percent nonfarm proprietors of total employed-across counties in Arkansas, Louisiana, and Mississippi. Three sets of predictor variables were used to better understand the determinants of these entrepreneurs: demographic/location, infrastructure, and socioeconomic. Results indicate that innovative entrepreneurs are more sensitive to highway proximity and rurality while non-innovative are more sensitive to educational attainment, creative class, and access to broadband. Important differences surface comparing innovative versus non-innovative versus nonfarm proprietors.
\end{abstract}

Keywords: entrepreneurship, economic development, innovative

JEL Codes: R11, L26

\section{INTRODUCTION}

Due in part to globalization, traditional economic development is becoming more competitive. Rural areas tend to be at a disadvantage when competing in a global economy because of many factors, including lack of workers, low educational attainment, and lack of appropriate infrastructure among others. However, an emerging economic development strategy-entrepreneurship - is being adopted by communities across America. Entrepreneurship has the intrinsic nature to bypass the same disadvantages that push rural areas to the bottom of a global list.

More importantly, recent research has shown that a robust positive relationship between small, locally-owned firms and per capita income growth exists (Fleming and Goetz, 2011) and that young businesses are important and contribute substantially to both gross and net job creation (Haltiwanger, Jarmin, and Miranda, 2010). Increasing per capita income and job creation, as recent research has shown, is possible by pursuing an entrepreneurship economic development strategy, which is an ideal recipe to fight poverty. Thus, better understanding entrepreneurship in a regional, high-poverty, and rural context is critical to informing development of such an economic development strategy.

This shift in economic development strategy is part of a lengthy evolution that started by recruiting external firms (i.e. smokestack chasing) and has now moved to focusing on innovation

Gallardo and Scammahorn are, respectively, Assistant Extension Professor and Graduate Research Assistant at the Southern Rural Development Center, Mississippi State University, Box 9656, Mississippi State, MS, 39762, USA

Corresponding Author: Roberto Gallardo, E-mail: robertog@,srdc.msstate.edu.

(C) Southern Regional Science Association 2012.

ISSN 1553-0892, 0048-749X (online)

www.srsa.org/rrs 
and entrepreneurship. This latter stage, also called the third wave, began in the early 1990s and continues to evolve (Bradshaw and Blakely, 1999; Hembd, 2008). Further, according to the Center for Enterprise Development, entrepreneurship has the potential to revive and strengthen rural economies. Similarly, because of the ineffectiveness of traditional economic development strategies in rural areas, these areas are focusing on entrepreneurship and endogenous growth (Rowe et al., 1999).

However, some confusion exists as to what exactly an entrepreneur is. Multiple definitions and types of entrepreneurs have been identified, making it important to properly define an entrepreneur. For this research, we will utilize the definition and two main types of entrepreneurs identified by Low (2009): innovative (entrepreneurial) and non-innovative (necessity/lifestyle). This typology was selected over traditional typologies (see Goetz and Rupasingha, 2009; Low, 2005) for two main reasons. First, this typology is unique in that it differentiates types of entrepreneurs based on the characteristics of the industries in which they start their business, compared to a "capture-all" category such as the percent nonfarm proprietors of total employed. Second, this typology has not been used in regional studies, and, thus, supporting or rejecting it contributes to the regional entrepreneurship literature. Therefore, it is important to not only include an entrepreneur program in economic development planning, but also to understand the needs, potential, and limitations of these entrepreneurs as well.

The objective of this study is to better understand the determinants and differences between these two types of entrepreneurs to help communities, especially poor and rural, design and implement more efficient entrepreneur strategies. The following section looks at a brief review of the literature regarding entrepreneurship. The data and methods utilized for this research study are discussed later, followed by the results of the statistical analysis. Lastly, a series of conclusions and main findings are discussed.

\section{BRIEF OVERVIEW OF THE ENTREPRENEURSHIP LITERATURE}

According to the literature discussed below, multiple indicators used in entrepreneurship models, the majority at the county-level, fall under three broad categories: demographic/location, infrastructure, and socioeconomic variables. In an interesting study, Florida (2002) tested the relationship between concentrations of bohemians - producers of cultural and creative assets with concentrations of human capital and to clusters of high-technology industries in cities across the country. The underlying hypothesis was that "a bohemian presence in an area helps establish an environment that attracts other talented or high human capital individuals" (Florida, 2002, p. 67). Results support the hypothesis, indicating (1) that bohemians tend to concentrate in particular areas and (2) a strong relationship exists between bohemians, high human capital, and clusters of high-tech industries. The author concludes that a high concentration of bohemians generate a context that is conducive to "the birth, growth and development of new and hightechnology industries" (Florida, 2002, p. 68). Thus, concentrations of bohemians and educational attainment need to be included in any entrepreneurship model.

On the other hand, McGranahan et al. (2010) argue not only that a "bohemian" climate is critical, but also opportunities for outdoor recreation. In this sense, the authors argue that creative-class workers are attracted to areas with high quantities of outdoor amenities as well as areas with an entrepreneurial context. This attraction of creative workers, in turn, generates local economic growth. In other words, though nonmetropolitan counties with higher proportions of creative class and richer entrepreneurial contexts had larger gains of establishments and jobs 
during the 1990s, the presence of medium to high quantities of local outdoor amenities was critical, as low amenities communities did not experience this same growth. Therefore, not all rural communities have the same potential to attract or develop talented entrepreneurs due to two different growth regimes in rural areas. One regime has a medium or high level of natural amenities and so has a vibrant entrepreneurial and creative class, while regimes with low amenities rely more heavily on recruiting external industries. Consideration of the level of natural amenities should also be incorporated into entrepreneurship models.

Since location and level of amenities matter, Goetz and Rupasingha (2009) looked at the change in the densities of nonfarm proprietors over a ten-year period, controlling for spatial correlation in addition to demographic, regional, and policy characteristics. Their findings indicate that nonfarm proprietor densities increased where the average age was higher, amenity levels were greater, counties were nonmetropolitan, prior economic growth was experienced, industry concentration in the construction and service sectors was greater, personal collateral was higher (percent owner-occupied homes and median housing values), and female labor force participation was higher. On the other hand, the authors found that a greater ethnic diversity, higher volumes of local bank deposits, and a higher educational attainment (but not high school graduates) reduced densities of nonfarm proprietors. Thus, spatial autocorrelation and policy characteristics also need to be accounted for in entrepreneurship models, in addition to demographic and economic factors.

While also considering regional variances and geography, Low et al. (2005) conducted a study to better understand how to gauge a region's entrepreneurial capacity. The authors differentiated between quantity and quality of entrepreneurs. The quantity of entrepreneurs was measured by calculating entrepreneurial breadth (the share of total employed who are nonfarm proprietors) while the quality of entrepreneurs was measured by calculating entrepreneurial depth both through the average income (average income of nonfarm proprietors) and through revenue capture (ratio of income to total revenue).

The authors then conducted statistical analysis to better understand what factors affected these different entrepreneurship measures. Their findings include that the local economy, human capital (including creative occupations), amenities, financial capital, and infrastructure affect the quantity and quality of entrepreneurs. The authors also found differences between urban and rural regions, with the latter having more breadth while the former have more depth. Therefore, entrepreneurial models need to account for level of rurality and a region's entrepreneurial capacity.

In a later study, Low (2009) further refined the definition of entrepreneur to include three main components: owner or operator, risk or uncertainty bearing, and innovator. According to the author, the innovator component is the key in that it creates a "novel combination of goods, services, and markets in response to economic opportunities, differentiating themselves from small business owners who do not innovate" (Low, 2009, p. 12). These entrepreneurial industries require both high technology and high-skill levels, and have a major impact on regional growth. Based on these criteria, the author identified a list of 37 entrepreneurial industries at the five-digit level NAICS code (see Low, 2009, Appendix A).

Low (2009) also found that growth in entrepreneurial industries were affected by "nontraditional" entrepreneurs in that they were younger, female, and less educated as compared to previous studies that said entrepreneurs are older, male, more highly educated, and white. The 
author noted that some results were inconsistent with prevailing theory and, hence, suggested that cautious interpretation is required. Nonetheless, it was clear from the analysis that the distinction between types of entrepreneurs should be accounted for in entrepreneurship models.

\section{DATA AND METHODS}

In order to better understand what factors affect the two types of entrepreneurs discussed in the previous section, two models - one using innovative nonemployers and the other using non-innovative nonemployers as the dependent variable-were analyzed using ordinary least square (OLS) regressions. These OLS regressions included spatial dependence diagnostics ${ }^{1}$ using a queen-contiguity weights matrix. All counties and parishes in Arkansas, Louisiana, and Mississippi were selected. This particular region was selected for two main reasons. First, this mostly rural region has above-average poverty rates. Second, this region has a traditionalistic political culture ${ }^{2}$ thus controlling for any variation in public policy affecting entrepreneurship strategies. Due to data availability, this study is cross-sectional and uses county-level data. The majority of indicators used the 2009 five-year American Community Survey ${ }^{3}$ with the exception of innovative nonemployers and non-innovative nonemployers (2009), broadband availability (2010), ${ }^{4}$ amenities scale (USDA, 2004), relative rurality (2000), distress and risk (2007), and the Gini coefficient (2000).

\subsection{Measuring Entrepreneurship}

Several entrepreneurship studies have used the share of all employed who are nonfarm proprietors (self-employed) a measure of entrepreneurship (Goetz and Rupasingha, 2009; Low et al., 2005). For this research we use two measures of entrepreneurs to differentiate between those entrepreneurs in innovative industries from those in non-innovative industries (Low, 2009). The two measures ${ }^{5}$ used include: percent innovative nonemployer establishments of total establishments and percent non-innovative nonemployer establishments (all other except innovative nonemployer establishments) of total establishments, which includes those with paid employees and those with no employees. In addition, a third model using the "traditional" entrepreneurship measure, percent nonfarm proprietors of total employed, was conducted to compare both metrics. Figures 1 and 2 show variation exists in both novel measures across the study area.

\footnotetext{
${ }^{1}$ Classic OLS regressions with spatial dependence diagnostics were conducted using GeoDa. Further analysis indicated that the results of the Lagrange multiplier (error) was significant thus a spatial error model was used.

${ }^{2}$ According to Elazar (1984) states have a dominant political culture (based on migration patterns of distinct racial, ethnic, and religious groups in the country) that view politics, bureaucracy, and government in different ways. Traditionalistic political culture uses government to maintain hierarchical order and defend traditional values.

${ }^{3}$ Five-year ACS data was utilized to avoid missing data on rural counties within the study area. Five-year ACS contains data for counties whose population is under 20,000 people. Many counties in our study area contain less than 20,000 residents.

${ }^{4}$ The temporal assumption required for OLS regressions is violated since this variable is for a year (2010) after the dependent variables (2009). However, we assume the changes in broadband providers between 2009 and 2010 were statistically insignificant.

${ }^{5}$ Pearson's correlation coefficient between both measures was -0.22 and statistically significant at the 0.01 level.
} 
FIGURE 1. Innovative Nonemployers in the Study Area by Quartiles

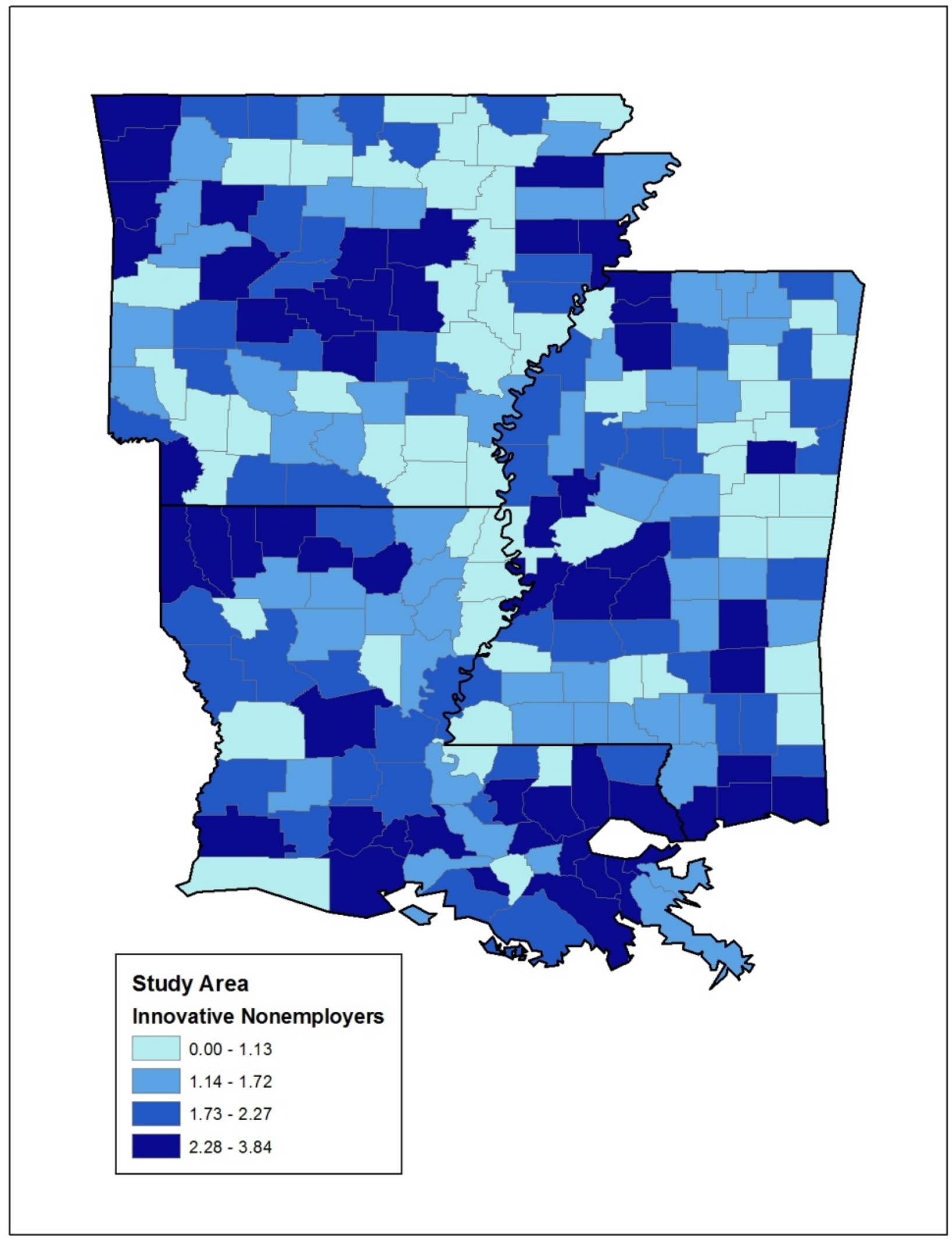

(C) Southern Regional Science Association 2012. 
FIGURE 2. Non-Innovative Nonemployers in the Study Area by Quartiles

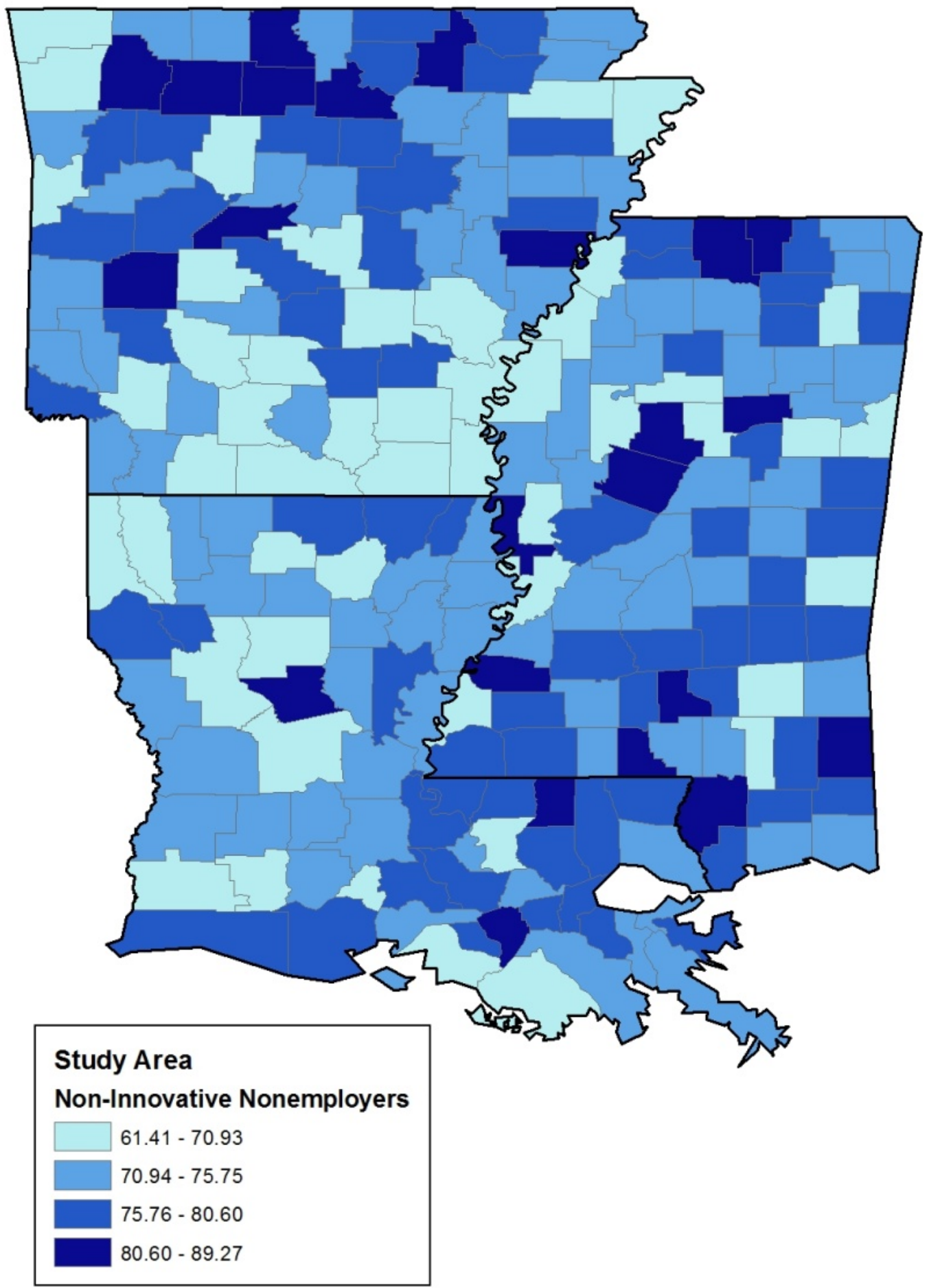

(C) Southern Regional Science Association 2012. 


\subsection{Control Variables}

As discussed previously, three categories of control variables were identified: demographic/location, infrastructure, and socioeconomic. For a statistical summary of variables utilized, please refer to Table 1. Demographic/location variables include rurality, race/ethnicity, median age, educational attainment, and percent foreign born. The rurality variable controls for differences in urban versus rural. The index of relative rurality utilized incorporates four dimensions of rurality, including population size, population density, percentage of urban residents, and distance to metropolitan areas (Waldorf, 2006). This index was selected because it is continuous in nature and does not create artificial similarities and/or separations that traditional rurality measures, such as U.S. Census urban areas, core-based statistical areas, and urban continuum, do (Waldorf, 2006). This index ranges from 0 to 100, with 100 denoting extremely high rurality and zero extremely low rurality (Waldorf, 2006).

An index of ethnic fragmentation was used to control for differences in race/ethnicity. The index ranges from 0 to 100 , with zero indicating a homogeneous community and 100 indicating a heterogeneous community (Alesina et al., 1999). Median age was used to control for age differences between counties/parishes. Similarly, two variables were used to control for educational attainment: the percent of those 25 years or older with less than a high school diploma or equivalent, as well as the percent with a bachelor's degree or more. Finally, the percent foreign born of total population was included.

Table 1: Summary Statistics for Study Region

\begin{tabular}{|c|c|c|c|c|c|}
\hline Variable & Obs. & Mean & Std. Dev. & Min & Max \\
\hline \multicolumn{6}{|l|}{ Criterion Variables } \\
\hline \% Innovative nonemp. est. & 221 & 1.7 & 0.87 & 0 & 3.8 \\
\hline \% Non-innovative nonemp.est. & 221 & 74.8 & 4.8 & 61.4 & 89.3 \\
\hline$\%$ Nonfarm proprietors total emp. & 221 & 23.1 & 8.3 & 4.2 & 59.8 \\
\hline \multicolumn{6}{|l|}{ Demographics/Location } \\
\hline Relative rurality & 221 & 55.5 & 13.9 & 12.1 & 79.9 \\
\hline Ethnic fragmentation & 221 & 39.4 & 14.7 & 5.2 & 68.1 \\
\hline Median age & 221 & 37.2 & 3.8 & 24.3 & 49.7 \\
\hline \% less than high school & 221 & 23.4 & 5.9 & 11.7 & 42.6 \\
\hline$\%$ bachelor's or more & 221 & 14.6 & 5.8 & 6.3 & 41.1 \\
\hline$\%$ foreign born & 221 & 1.8 & 2.1 & 0 & 17.4 \\
\hline \multicolumn{6}{|l|}{ Infrastructure } \\
\hline Natural amenities & 221 & 3.34 & 0.57 & 2 & 5 \\
\hline Interstate access & 221 & 0.27 & 0.44 & 0 & 1 \\
\hline Broadband providers & 221 & 4.05 & 4.22 & 0.03 & 54.4 \\
\hline \multicolumn{6}{|l|}{ Socioeconomic } \\
\hline Distress & 221 & 0.33 & 0.47 & 0 & 1 \\
\hline Risk & 221 & 0.31 & 0.46 & 0 & 1 \\
\hline Median household income & 221 & 35,058 & 7,829 & 20,250 & 60,874 \\
\hline Homeownership rate & 221 & 71.77 & 8.1 & 47.2 & 88.6 \\
\hline Gini coefficient & 221 & 45.88 & 3.44 & 36.5 & 60.6 \\
\hline$\%$ creative occupations & 221 & 27.6 & 4.5 & 10.7 & 44.7 \\
\hline
\end{tabular}

(C) Southern Regional Science Association 2012. 
Infrastructure variables include number of unique broadband providers aggregated from block level data obtained from the National Telecommunication and Information Administration (NTIA) and its national broadband map project per 10,000 residents in the civilian labor force. This group also includes a dichotomous variable indicating if an interstate runs through the particular county, as well as a score ranking the county's natural amenities ranging from 1 to 7 , with a lower score indicating less natural amenities and a higher score indicating more natural amenities (McGranahan, 1999).

Finally, socioeconomic variables include a distress and at-risk indicator. Distress and atrisk counties were identified by request of the Appalachian Regional Commission based on a composite measure of population change, employment/population ratio, share of adults with at least a year of college, poverty rate, and per capita market income (Partridge et al., 2009). Workers employed in creative occupations were also included in this category to control for the type of workers that may want to start a business, as discussed in the previous section. Median household income is included to control for wealth availability in addition to the homeownership rate and the Gini income distribution coefficient. The Gini coefficient ranges from 0 to 100, with 0 indicating a perfect distribution of income and 100 indicating an unequal income distribution.

\section{RESULTS}

The results of the OLS regressions conducted are shown in Tables 2, 3, and 4. Model 1 used percent innovative nonemployer establishments of total establishments as the criterion variable; Model 2 used percent non-innovative establishments of total establishments as the criterion variable; Model 3 used percent nonfarm proprietors of total employed. All models were tested for heteroskedasticity and multicollinearity. ${ }^{6}$ A total of 15 variables in three groups, identified from the literature, were used as predictor variables.

As shown in Table 2, Model 1 was statistically significant $(p<0.00)$ and explained 50 percent of the variance (adjusted $R^{2}=.50$ ) in percent innovative nonemployer establishments of total businesses across Arkansas, Louisiana, and Mississippi. Two variables of the demographic/location category had a statistically significant correlation with the dependent variable: relative rurality and percent of adults with a bachelor's or more. The former had a negative relationship while the latter had a positive relationship. In other words, the more rural a county, the lower the share of all businesses that are innovative nonemployer establishments. At the same time, the more educated the county, the higher the share of innovative nonemployer establishments. From the infrastructure category, only proximity to an interstate highway had a positive statistically significant impact on the dependent variable. Thus, having an interstate highway in the county increased the percent of innovative nonemployer establishments. From the socioeconomic category, homeownership had a positive statistically significant relationship with percent innovative nonemployer establishments. As homeownership increases, so do innovative nonemployer establishments.

Results regarding the percent non-innovative nonemployer establishments were a bit more complex. Model 2a was statistically significant $(p<0.00)$ and explained 54 percent of the variance (adjusted $R^{2}=.54$ ) in the percent of non-innovative nonemployer establishments in the

\footnotetext{
${ }^{6}$ White's Test was conducted indicating homoscedasticity; variable influence factor (VIF) test was conducted resulting in an average VIF score for models 1 and 2 of 2.50; average VIF score for model 3 was 2.51
}

(C) Southern Regional Science Association 2012. 


\section{TABLE 2. Model 1 (Innovative) Classic OLS Results with Spatial Dependence Diagnostics}

\begin{tabular}{lr}
\hline Variables & $\begin{array}{l}\text { Coefficients } \\
(p \text {-values })\end{array}$ \\
\hline Demographic/Location & $-0.02(0.00)$ \\
$\quad$ Relative Rurality & $-0.00(0.24)$ \\
$\quad$ Ethnic Fragmentation & $-0.01(0.20)$ \\
$\quad$ Median Age & $-0.00(0.83)$ \\
\% Less than High School & $+0.03(0.03)$ \\
$\quad \%$ Bachelor's or More & $+0.00(0.87)$ \\
$\quad \%$ Foreign Born & \\
Infrastructure & $0.02(0.72)$ \\
$\quad$ Natural Amenities Scale & $+0.27(0.01)$ \\
$\quad$ Interstate Proximity & $-0.01(0.12)$ \\
$\quad$ Broadband Providers & \\
Socioeconomic & $-0.20(0.23)$ \\
$\quad$ Distress & $-0.10(0.44)$ \\
$\quad$ Risk & $+0.00(0.65)$ \\
$\quad$ Median Household Income & $+0.01(0.02)$ \\
$\quad$ Homeownership & $+0.00(0.89)$ \\
$\quad$ Gini Coefficient & $+0.00(0.95)$ \\
$\quad$ Creative Occupations & .50 \\
Adjusted $R^{2}$ & $16.06(0.01)$ \\
F-score & -0.97 \\
Lagrange multiplier (lag) & -0.3 \\
\hline \hline
\end{tabular}

same region. However, spatial autocorrelation was detected and Lagrange Multiplier tests suggested a spatial error model be used; results are shown in Model $2 \mathrm{~b}$.

Results regarding the percent non-innovative nonemployer establishments were a bit more complex. Model 2a was statistically significant $(p<0.00)$ and explained 54 percent of the variance (adjusted $R^{2}=.54$ ) in the percent of non-innovative nonemployer establishments in the same region. However, spatial autocorrelation was detected and Lagrange Multiplier tests suggested a spatial error model be used; results are shown in Model $2 \mathrm{~b}$.

From the demographic/location category, both ethnic fragmentation and percent of adults with bachelor's degree or more had a negative statistically significant impact on the dependent variable. In other words, as the community becomes more diverse and educated, the percent of non-innovative , nonemployer establishments decrease. Important to note is that relative rurality was statistically significant in model 2 a but after accounting for spatial autocorrelation the 
statistical significance was lost. Thus, the change in significance regarding rurality was the only substantive difference between the classical OLS model and spatial error model.

As for the infrastructure category, as the percent of unique broadband providers per 10,000 residents in the civilian labor force increases, so do the non-innovative entrepreneurs. This variable was not statistically significant when looking at percent innovative nonemployer establishments. This finding will be discussed more in depth in the next section. Finally, as homeownership and the percent of workers in creative occupations increase, so do noninnovative entrepreneurs.

TABLE 3. Model 2 (Non-Innovative) OLS Results with Spatial Dependence Diagnostics

\begin{tabular}{|c|c|c|}
\hline & $\begin{array}{c}\text { Model 2a } \\
\text { Classic OLS }\end{array}$ & $\begin{array}{c}\text { Model 2b } \\
\text { Spatial Error }\end{array}$ \\
\hline Variables & $\begin{array}{l}\text { Coefficients } \\
(p \text {-values })\end{array}$ & $\begin{array}{l}\text { Coefficients } \\
(p \text {-values })\end{array}$ \\
\hline \multicolumn{3}{|l|}{ Demographic/Location } \\
\hline Relative Rurality & $-0.04(0.05)$ & $-0.02(0.45)$ \\
\hline Ethnic Fragmentation & $-0.06(0.00)$ & $-0.06(0.00)$ \\
\hline Median Age & $-0.11(0.15)$ & $-0.12(0.12)$ \\
\hline \% Less than High School & $+0.01(0.80)$ & $-0.01(0.94)$ \\
\hline \% Bachelor's or More & $-0.22(0.00)$ & $-0.27(0.00)$ \\
\hline \% Foreign Born & $+0.02(0.84)$ & $+0.01(0.89)$ \\
\hline \multicolumn{3}{|l|}{ Infrastructure } \\
\hline Natural Amenities Scale & $+0.01(0.97)$ & $-0.08(0.84)$ \\
\hline Interstate Proximity & $+0.65(0.26)$ & $+0.54(0.34)$ \\
\hline Broadband Providers & $+0.17(0.00)$ & $+0.16(0.00)$ \\
\hline \multicolumn{3}{|l|}{ Socioeconomic } \\
\hline Distress & $+0.40(0.64)$ & $+0.11(0.89)$ \\
\hline Risk & $+0.31(0.66)$ & $+0.33(0.62)$ \\
\hline Median Household Income & $-0.00(0.84)$ & $+0.00(0.61)$ \\
\hline Homeownership & $+0.23(0.00)$ & $+0.19(0.00)$ \\
\hline Gini Coefficient & $-0.06(0.47)$ & $-0.04(0.65)$ \\
\hline Creative Occupations & $+0.45(0.00)$ & $+0.47(0.00)$ \\
\hline Adjusted $R^{2} / R^{2}$ & .54 & .58 \\
\hline$F$-score & $19.90(0.01)$ & --- \\
\hline Lambda & --- & $0.26(0.00)$ \\
\hline Lagrange multiplier (lag) - $p$ value & 0.79 & --- \\
\hline Lagrange multiplier (error) $-p$ value & 0.04 & --- \\
\hline$n$ & 221 & 221 \\
\hline
\end{tabular}

(C) Southern Regional Science Association 2012. 
Results using the "traditional" entrepreneurship indicator-percent nonfarm proprietors (self-employed) of total employed - are slightly different. The model explains 41 percent of the variance in self-employed (adjusted $R^{2}=.41$ ). Two indicators from the demographic/location category had significant relationships with the percent of nonfarm proprietors. As median age increases, so does the percent of self-employed. As the share of foreign-born increases, the share of self-employed decreases. Regarding infrastructure, as the number of broadband providers per 10,000 residents in the labor force increases, so do the self-employed as a share of total employed. Finally, as both homeownership and the share of creative occupations increase so does the share of self-employed from the socioeconomic category.

\section{DISCUSSION AND CONCLUSIONS}

Innovative entrepreneurs are much more sensitive to location-specifically rurality and availability of interstate highways. Perhaps these types of entrepreneurs require a certain critical mass in their market niches for them to strive, and this critical mass is not available in rural areas. Similarly, having access to an interstate affects innovative entrepreneurs, in that the goods and services they produce are more than likely exported out of the region. Not having an adequate transportation infrastructure undermines their ability to conduct business. Finally, homeownership has a positive effect on innovative entrepreneurs in that they have access to

TABLE 4. Model 3 (Nonfarm Proprietors) OLS Results and Spatial Dependence Diagnostics

\begin{tabular}{lr}
\hline \hline & Coefficient (p value) \\
\hline Demographic/Location & $-0.10(0.08)$ \\
$\quad$ Relative Rurality & $-0.00(0.86)$ \\
Ethnic Fragmentation & $+0.39(0.01)$ \\
Median Age & $-0.02(0.87)$ \\
\% Less than High School & $-0.13(0.37)$ \\
\% Bachelor's or More & $-0.61(0.01)$ \\
Foreign Born & \\
$\quad$ Natural Amenities Scale & \\
Interstate Proximity & $+0.43(0.61)$ \\
$\quad$ Broadband Providers & $-0.13(0.90)$ \\
Socioeconomic & $+0.41(0.00)$ \\
$\quad$ Distress & \\
Risk & $-0.85(0.62)$ \\
$\quad$ Median Household Income & $-1.61(0.25)$ \\
$\quad$ Homeownership & $-0.00(0.99)$ \\
$\quad$ Gini Coefficient & $+0.22(0.00)$ \\
$\quad$ Creative Occupations & $-0.24(0.21)$ \\
Adjusted $R^{2}$ & $+0.71(0.00)$ \\
F-score & 0.41 \\
Lagrange multiplier (lag) & -0.99 \\
Lagrange multiplier (error) & -0.38 \\
$n \quad$ & 221 \\
\hline \hline
\end{tabular}

(C) Southern Regional Science Association 2012. 
home-equity loans to start their business. This makes sense since most of the industries identified by Low (2009) as innovative entrepreneurial industries require a higher capital investment.

Regarding the non-innovative entrepreneurs, the negative relationships between the percent of those with a bachelor's or more, as well as the increased racial/ethnic diversity of a community are similar to what Goetz and Rupasingha (2009) found using growth in a "captureall" entrepreneurship metric. Though these findings were somewhat unexpected, future research should look at these relationships more in depth since these relationships are probably due to the nature of rural contexts and not one feature driving the other. Further, Goetz and Rupasingha (2009) found that as the average age increased, so did the self-employed density over time, while our findings do not show a relationship between age and both types of entrepreneurs. A likely explanation for this may be that our study is cross-sectional (looking at only one year), while their study looked at a ten-year period.

Perhaps, more importantly, is the fact that as the number of broadband providers increases, so do non-innovative entrepreneurs. This highlights the fact that broadband availability is critical to the vast majority of entrepreneurs since innovative entrepreneurs include a small percentage of overall entrepreneurs. Because innovative entrepreneurs are less likely to start businesses in rural America for the reasons discussed above, increasing broadband availability will enhance the development of non-innovative entrepreneurs.

It is interesting to note that as non-innovative entrepreneurs increase, income inequality decreases. This relationship should be explored more in depth in future research. Although this relationship is not statistically significant $(p<.65)$ it raises important questions because the direction of the relationship is opposite and more statistically significant than the one seen with innovative entrepreneurs $(p<.89)$. Thus, pursuing non-innovative entrepreneurs may help reduce income inequality.

Similarly, creative workers had a statistically significant relationship with non-innovative entrepreneurs but not with innovative entrepreneurs. The fact that creative workers are associated with one type of entrepreneur but not the other highlights the importance of distinguishing between entrepreneurs and not capturing them in one metric. Interestingly, the number of amenities had no relationship with either type of entrepreneur. This finding is inconsistent with those reported by McGranahan (2010) and Florida (2002). A reason may be that the present study focused on just three southern states. Future research should drill deeper into this issue since the findings from this research imply that amenities yield marginal value when defining where both types of entrepreneurs locate, at least in the three states analyzed.

A relationship between a high educational attainment (bachelor's or more) and both innovative entrepreneurs and non-innovative entrepreneurs exists. However, the relationship is positive with innovative entrepreneurs and negative with non-innovative entrepreneurs. Perhaps a higher educational level is necessary with innovative entrepreneurs due to the nature of their businesses while a higher education may not be needed for non-innovative entrepreneurs. Another reason may be that less educated people are found in rural areas where non-innovative entrepreneurs are more prevalent. These findings contradict what Goetz and Rupasingha (2009) and Low (2009) found in that there is no relationship between higher educational attainment and entrepreneurship. But again, these findings are only generalizable to three southern states.

Based on the statistical results, it can be implied that creative workers do not necessarily have a high educational attainment, at least in these three southern states. In fact, Pearson's

(C) Southern Regional Science Association 2012. 
TABLE 5. Summary of Regression Results

\begin{tabular}{|c|c|c|c|}
\hline Variable & $\begin{array}{r}\text { Model } 1 \text { - OLS } \\
\text { (Innovative) }\end{array}$ & $\begin{array}{l}\text { Model 2b - SEM } \\
\text { (Non-Innovative) }\end{array}$ & $\begin{array}{r}\text { Model } 3 \text { - OLS } \\
\text { (Nonfarm) }\end{array}$ \\
\hline \multicolumn{4}{|l|}{ Demographic/Location } \\
\hline Relative Rurality & - & & \\
\hline Ethnic Fragmentation & & - & \\
\hline Median Age & & & + \\
\hline$\%$ Less than High & & & \\
\hline \multicolumn{4}{|l|}{ School } \\
\hline \% Bachelor's or More & + & - & \\
\hline \% Foreign Born & & & - \\
\hline \multicolumn{4}{|l|}{ Infrastructure } \\
\hline \multicolumn{4}{|l|}{ Natural Amenities Scale } \\
\hline Interstate Proximity & + & & \\
\hline Broadband Providers & & + & + \\
\hline \multicolumn{4}{|l|}{ Socioeconomic } \\
\hline \multicolumn{4}{|l|}{ Distress } \\
\hline \multicolumn{4}{|l|}{ Risk } \\
\hline \multicolumn{4}{|l|}{$\begin{array}{l}\text { Median Household } \\
\text { Income }\end{array}$} \\
\hline Homeownership & + & + & + \\
\hline \multicolumn{4}{|l|}{ Gini Coefficient } \\
\hline Creative Occupations & & + & + \\
\hline Adjusted $R^{2} / R^{2}$ & 0.54 & 0.58 & 0.41 \\
\hline
\end{tabular}

correlation coefficient between creative workers and a high educational attainment is not significant. Therefore, having more education does not necessarily mean working in creative occupations. This interplay affects both types of entrepreneurs in different ways. This needs to be kept in mind when designing entrepreneurship development systems, or EDS.

After comparing all measures (innovative versus non-innovative versus "traditional") shown in Table 5, three main points are worth discussing. First, only homeownership had a significant positive relationship with all three measures. In other words, as homeownership increases so does entrepreneurship, regardless of how it is measured. Second, the fact that relative rurality was significant when using innovative nonemployers but not using the "traditional" measure indicates that the latter overlooks the importance of rurality when dealing with different types of entrepreneurs. Assuming rurality is not important when designing entrepreneurship development systems may result in frustration and waste of scarce resources, particularly in rural areas. Third, higher levels of education among residents did not matter when using the "traditional" entrepreneurial measure, but had opposite impacts when differentiating entrepreneurs. Since rural areas are more likely to have less educated residents, understanding this difference can help rural communities better design and implement their entrepreneur development systems. In summary, using a typology that can differentiate among entrepreneurs 
based on the industry they are engaged in provides valuable information that traditional measures overlook and can make a big difference.

It is important to recognize some limitations of this study. First, results should be interpreted with caution since the innovative entrepreneurship typology utilized is itself not theoretically consistent. Nonetheless, the findings of this study contribute to the regional literature in that some of its findings were consistent with findings with national studies utilizing different entrepreneurship measures. Thus, in this specific region, this innovative typology was not fully inconsistent. Second, future research should also replicate this study at the national level since findings from this particular study are only generalizable to these three southern states. Third, the cross-sectional nature of this study is a limitation, and future studies should complement these findings with dynamic research designs.

To conclude, the fact that innovative and non-innovative entrepreneurs are each affected by different predictors is important to keep in mind. This is of crucial importance when designing and implementing entrepreneurship development strategies at local and regional levels. Findings from this research should help policymakers and/or community stakeholders better design and implement entrepreneurship strategies in their communities.

\section{REFERENCES}

Alesina, Alberto, Reza Baqir, and William Easterly. (1999) "Public Goods and Ethnic Divisions," Quarterly Journal of Economics, 114, 1243-1284.

Bradshaw, Ted K. and Edward J. Blakely. (1999) "What are 'Third-Wave' State Economic Development Efforts? From Incentives to Industrial Policy," Economic Development Quarterly, 13, 229-244.

Elazar, Daniel J. (1984) American Federalism: A View from the States, $3^{\text {rd }}$ ed. New York: Harper \& Row.

Fleming, David A. and Stephan J. Goetz. (2011) "Does Local Firm Ownership Matter?," Economic Development Quarterly, 25, 277-281.

Florida, Richard. (2002) "Bohemia and Economic Geography," Journal of Economic Geography, 2, 55-71.

Goetz, Stephan J. and Anil Rupasingha. (2009) "Determinants of Growth in Non-farm Proprietors in the U.S., 1990-2000," Small Business Economics, 32, 425-438.

Haltiwanger, John C., Ron S. Jarmin, and Javier Miranda. (2010) "Who Creates Jobs? Small vs. Large vs. Young," National Bureau of Economic Research, Working Paper 16300. Retrieved from http://www.nber.org/papers/w16300.

Hembd, Jerry. (2008) "Sustainable Development: Is It Going Mainstream? Building Communities Webinar Education Series Presentation, Northern Center for Community and Economic Development, University of Wisconsin. Retrieved from http://www.uwex.edu/ces/cced/communities/documents/Series9.pdf.

Low, Sarah H. (2009) Defining and Measuring Entrepreneurship for Regional Research: A New Approach. Unpublished Ph.D. dissertation, University of Illinois at Urbana-Champaign. Retrieved from http://hdl.handle.net/2142/14269. 
Low, Sarah H., Jason Henderson, and Stephan Weiler. (2005) "Gauging a Region's Entrepreneurial Potential," Federal Reserve Bank of Kansas City, Third Quarter, 61-89. Retrieved from http://www.kansascityfed.org/Publicat/econrev/PDF/3q05low.pdf.

McGranahan, David A. (1999) "Natural Amenities Drive Population Change," Agricultural Economics Report 781, Food and Rural Economics Division, Economic Research Service, U.S. Department of Agriculture. Available online: http://ers.usda.gov/Publications/AER781.

McGranahan, David A., Timothy R Wojan, and Dayton M. Lambert. (2010) "The Rural Growth Trifecta: Outdoor Amenities, Creative Class and Entrepreneurial Context," Journal of Economic Geography, 11, 529-557.

Partridge, Mark, Linda Lobao, Ayesha Enver, Wilner Jeanty, Bo Beaulieu, Richard Gallardo, and Stephan Goetz. (2009) "Developing and Assessing Potential Forward-Looking Distress Indicators for the Appalachian Region," Appalachian Regional Commission. Obtained from http://www.arc.gov/research/researchreportdetails.asp?REPORT_ID=88.

Rowe, Barbara R., George W. Haynes, and Kathryn Stafford. (1999) "The Contribution of Home-Based Business Income to Rural and Urban Economies," Economic Development Quarterly, 13, 66-77.

USDA-ERS (1999) Natural Amenities Scale. United States Department of Agriculture Economic Research Service. Obtained from: http://www.ers.usda.gov/Data/NaturalAmenities/.

Waldorf, Brigitte S. (2006) “A Continuous Multi-Dimensional Measure of Rurality” Moving Beyond Threshold Measures," Unpublished paper presented at the American Agricultural Economic Association Annual Meeting in Long Island, CA, July 24-27, 2006.

(C) Southern Regional Science Association 2012. 